\title{
Science Goals of the U.S. Department of the Interior Southeast Climate Science Center
}

In 2011, the U.S. Department of the Interior Southeast Climate Science Center (CSC) finalized the first draft of its goals for research needed to address the needs of natural and cultural partners for climate science in the Southeastern United States.

The science themes described in this draft plan were established to address the information needs of ecoregion conservation partnerships, such as the Landscape Conservation Cooperatives (LCCs) and other regional conservation-science and resource-management partners. These themes were developed using priorities defined by partners and stakeholders in the Southeast and on a large-scale, multidisciplinary project — the Southeast Regional Assessment Project (SERAP)—-developed in concert with those partners.

Science products developed under these themes will provide models of potential future conditions, assessments of likely impacts, and tools that can be used to inform the conservation management decisions of LCCs and other partners. This information will be critical as managers try to anticipate and adapt to climate change. Resource managers in the Southeast are requesting this type of information, in many cases as a result of observed climate change effects.

The Southeast CSC draft science plan identifies six science themes and frames the activities (tasks, with examples of recommended near-term work for each task included herein) related to each theme that are needed to achieve the objectives of the Southeast CSC.

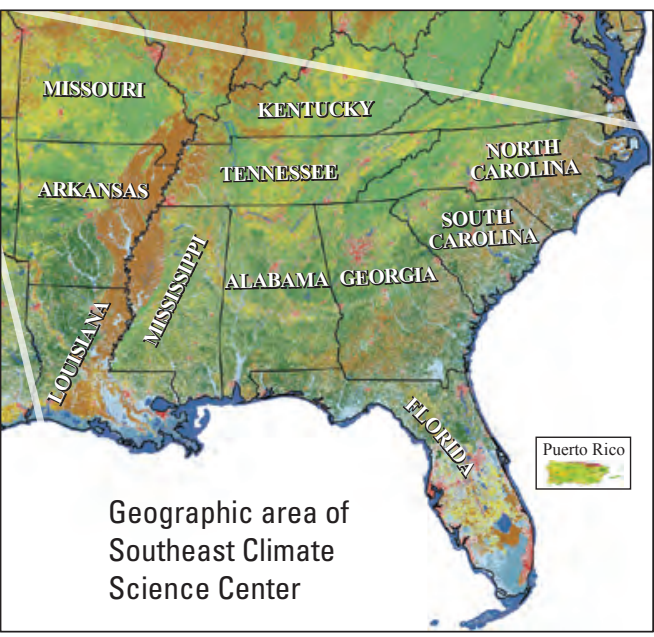

Geographic area of

\section{Science Theme 1: Climate and Other Appropriate Projections to Use for Resource Management}

\section{Task 1: Evaluate needed climate information within the frame of} Southeast CSC focus resources and study questions

Work with the conservation community, specifically through LCCs, using a structured decision-making process to identify resource-management questions and determine which downscaled information is the most useful for the problem identified.

\section{Task 2: Survey available and forthcoming global climate projections} Use the Coupled Model Intercomparison Project (CMIP3) information as the basis for Southeast CSC climate projections and evaluate potential use of upcoming CMIP5 projections.

Task 3: Decide whether and (or) how to cull and update global projections Use all available model projections from CMIP3.

\section{Task 4: Characterize how global projections can be downscaled and} bias corrected

Obtain available CMIP3 climate-projection information (raw AtmosphereOcean General Circulation Model [AOGCM] results and bias-corrected and (or) downscaled translations) over the Southeast. Evaluate the historical periods of simulation and evaluate simulation adequacy for the menu of climate conditions considered.

Task 5: Develop climate scenarios for Southeast CSC impacts, vulnerability, and adaptation assessments

Use information from Tasks 1 to 4 to construct climate change scenarios specific to the science needs of stakeholders in the Southeast. This includes working to characterize and quantify uncertainty in climate change projections to provide better information for CSC assessment activities.

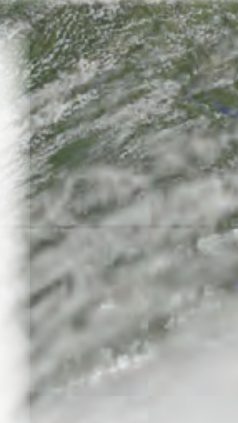



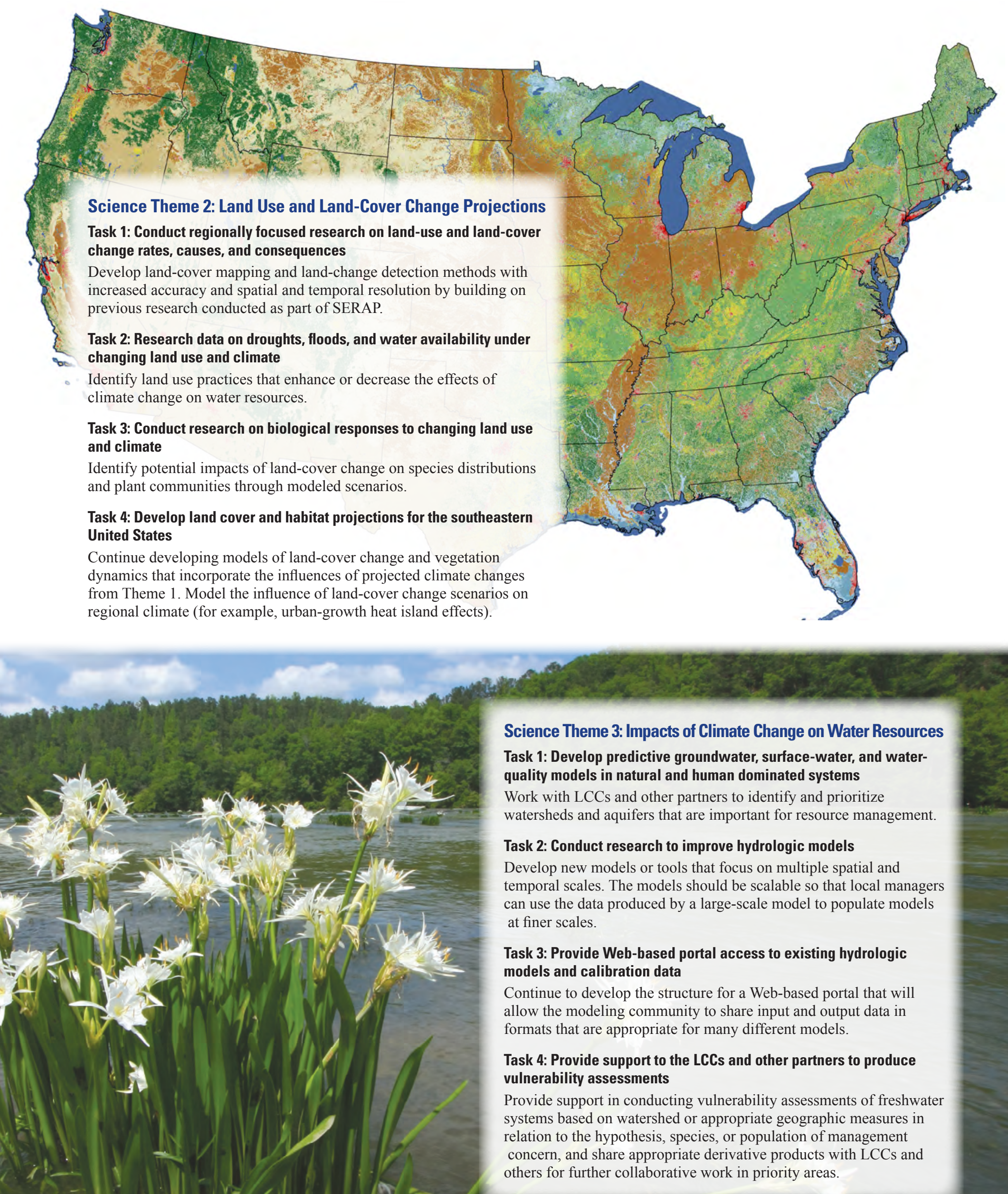


\section{Science Theme 4: Ecological Research and Modeling}

Task 1: In close collaboration with LCCs, States, and other stakeholders, determine the highest priority species and populations for the development of distribution maps and population or phenology models

In cooperation with partners and stakeholders, identify subsets of, and develop future distribution models for, a range of focal taxa, pest species, and foundation species.

Task 2: Test whether the predicted responses of species to climate change and land-use change match observed changes

Identify taxa for which data are available or can be made available to study historic (for example, during glacial cycles) responses to climate change or modern (last hundred years) responses to climate change.

\section{Task 3: Conduct laboratory and field experiments to document organismal responses to} climate change

Perform both observational and controlled experiments, such as climate chamber research, most germane to the focal taxa, pest species, and foundation species identified as priority species. Incorporate results from experiments into distribution, phenology, and abundance modeling approaches.

Task 4: Identify new or altered species interactions that are likely to have a disproportionate impact on community structure and ecosystem function

Use insights gained from executing Tasks 1-3 to identify pest and pathogen species that are likely to interact strongly with a new set of hosts, and anticipated new sets of predator-prey and competitive interactions that are likely to have large community or ecosystem consequences.

Task 5: Provide support to LCCs in assessing new strategies to conserve natural communities and ecosystems

Provide support to LCCs and other partners as they formulate a set of strategies to identify onthe-ground priorities for conservation that are most likely to protect biodiversity in the future but do not hinge on assumptions surrounding species-specific responses to climate change.
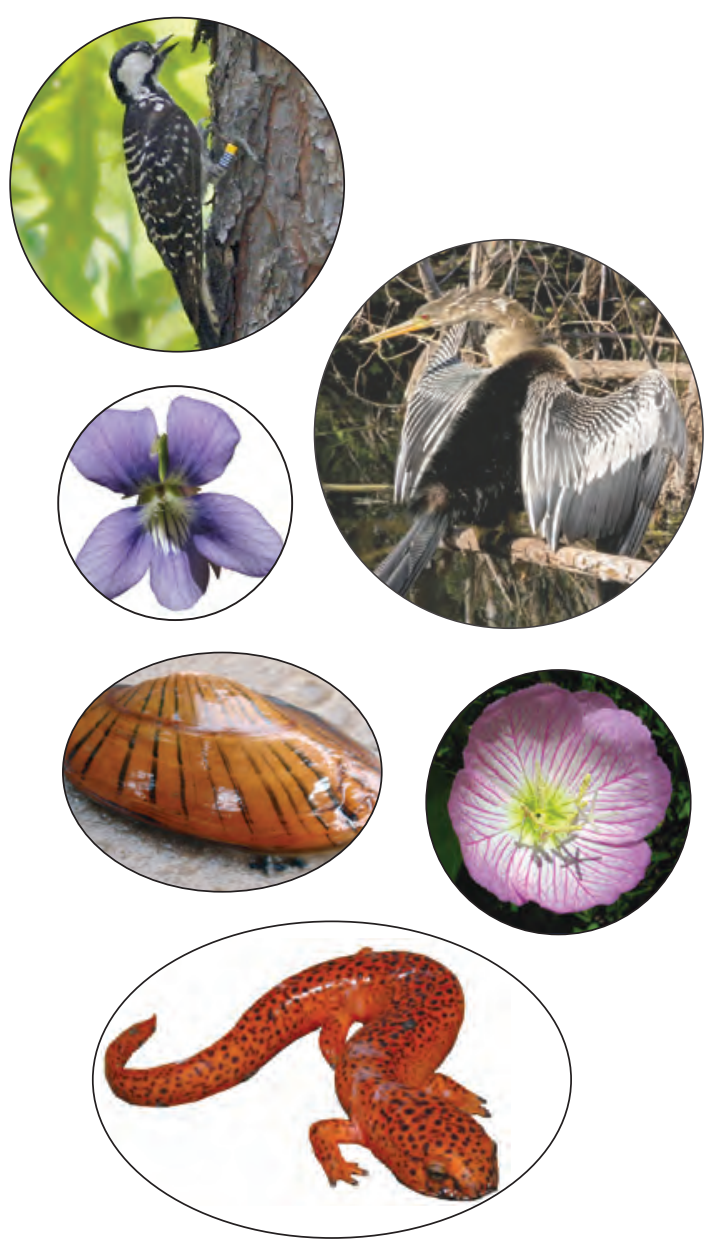

\section{Science Theme 5: Coastal and Nearshore Marine Environments}

Task 1: Establish ecological baseline conditions and describe current climate trends and impacts in coastal systems

Develop detailed maps of coastal habitats and species distributions in the South Atlantic and eastern Gulf of Mexico coastal zones building on work conducted during the SERAP.

\section{Task 2: Develop scenarios of coastal landform and habitat change}

Initiate process-oriented studies to quantitatively identify the effects of sea-level rise and other stressors on coastal systems for the southeastern coastal region using products created during the SERAP as a foundation.

Task 3: Describe how estuaries and marine resources are affected by increased temperature, sea-level rise, changes in runoff patterns to the coast, ocean acidification, and changes in the destructive potential of tropical storms

Identify field sites and candidate lists of organisms that can serve as marine ecosystem "sentinels" for early- warning purposes and develop standard operating procedures for long-term monitoring.

Task 4: Provide support in assessing potential impacts on highly vulnerable coastal and marine habitats Work with LCCs and other partners to develop a working list of priority coastal habitats and locations for the entire Southeast CSC.

\section{Task 5: Provide support for the assessment of potential management responses}

Provide support to the LCCs and other partners to identify how management of priority species and habitats from Theme 4 and cultural heritage resources from Theme 6 can incorporate climate and land-use change trends and projections from Themes 1 and 2.
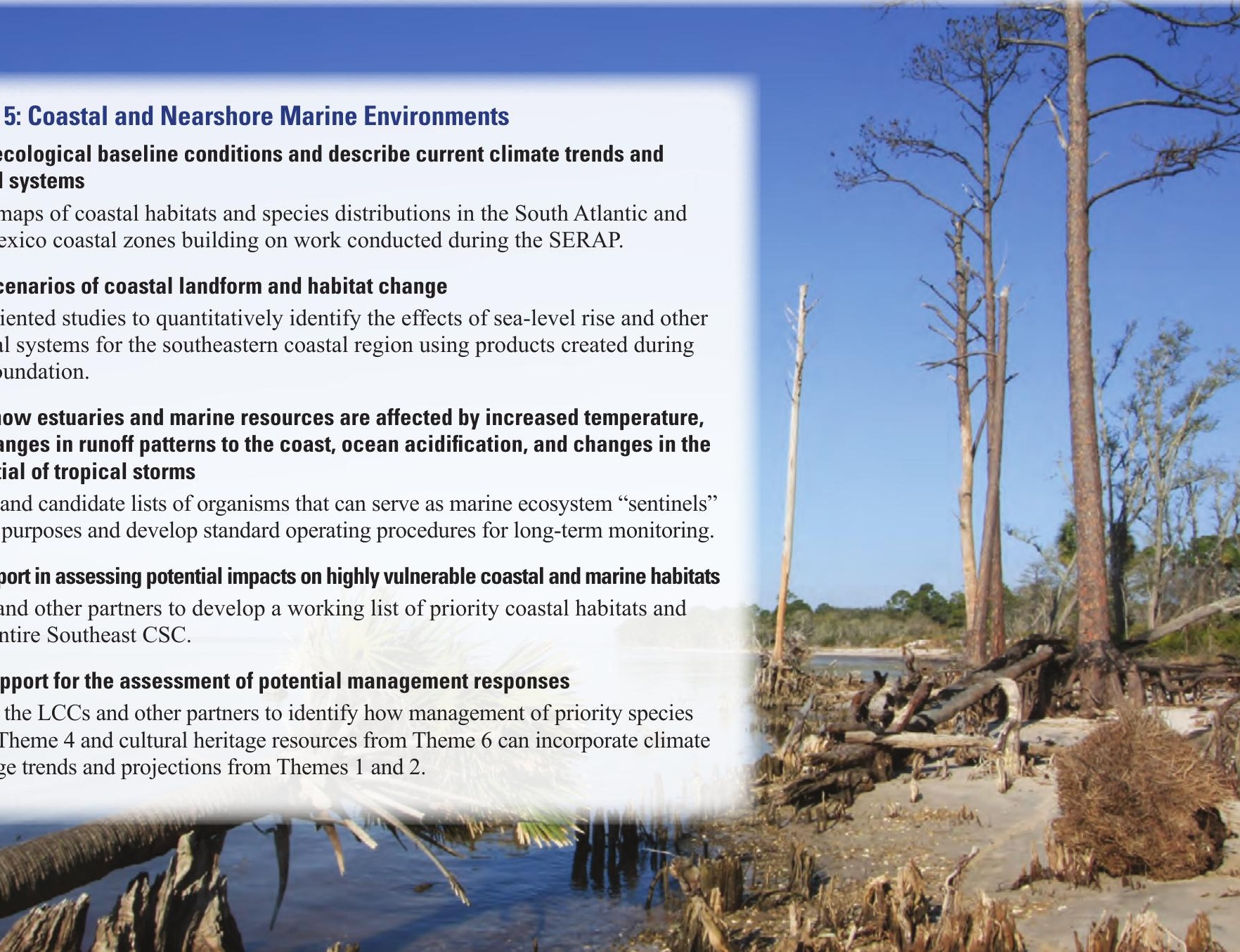


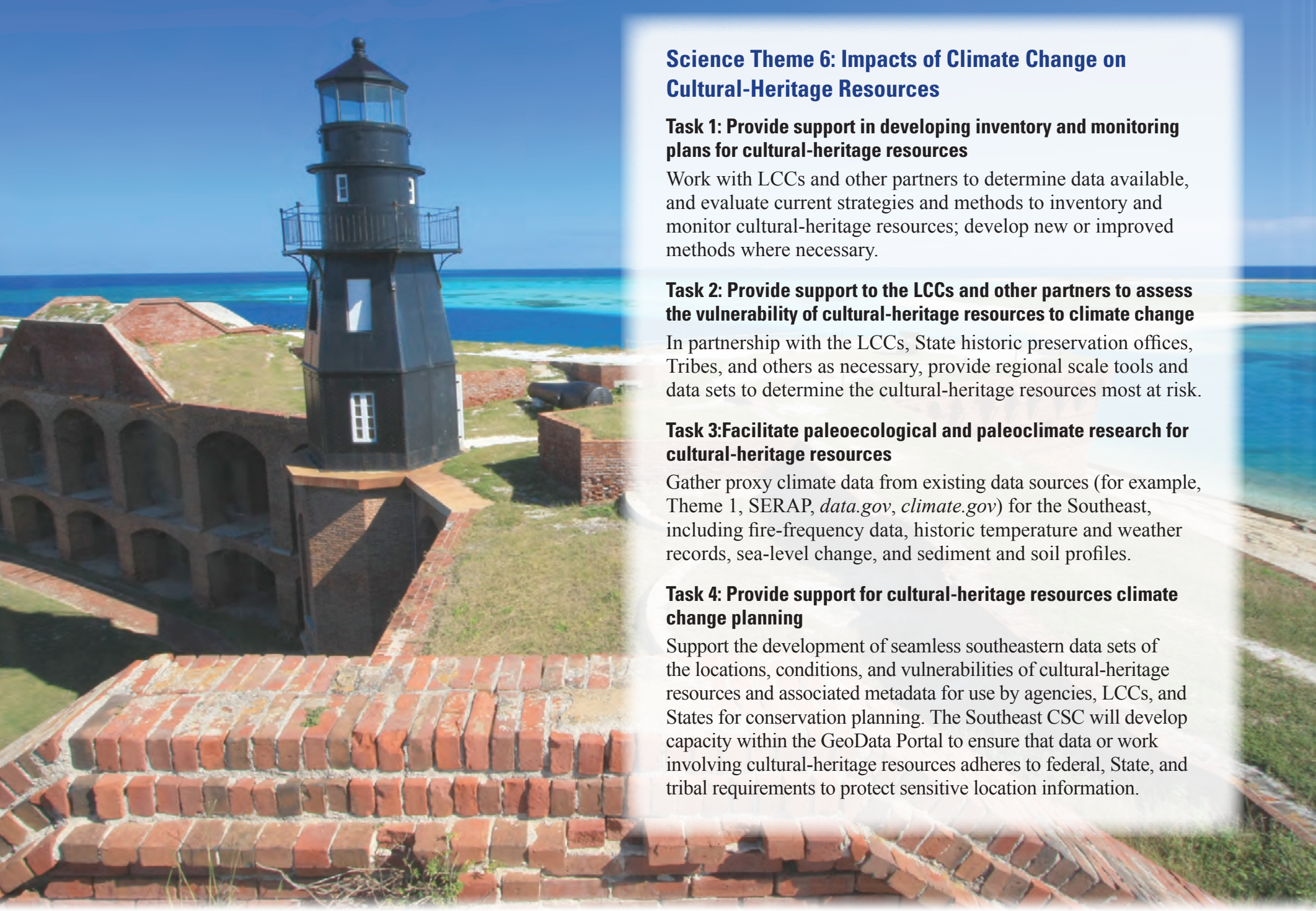

\section{Contact Information}

Gerard McMahon, Ph.D.

Director

DOI Southeast Climate Science Center

Department of Biology

240 David Clark Labs

North Carolina State University

Raleigh, North Carolina 27695-7617

Phone: 919-515-2229 e-mail: gmcmahon@usgs.gov

Damian Shea, Ph.D.

Professor of Biology and

Environmental Toxicology

Department of Biology

142 David Clark Labs,

Campus Box 7617

North Carolina State University

Raleigh, North Carolina 27695-7617

Phone 919-513-3065

e-mail: d_shea@ncsu.edu

For more information please visit http://www.theglobalchangeforum.org/se-csc/

\section{Acronyms Used in this Fact Sheet}

AOGCM Atmosphere-Ocean General Circulation Model

CMIP Coupled Model Intercomparison Project

CSC Climate Science Center

LCCs Landscape Conservation Cooperatives

SERAP Southeast Regional Assessment Project
Photo credits:

Page 1, bottom: Hurricane Irene, accessed September 8, 2011, at http://www.nasa.gov/mission_pages/hurricanes/archives/ 2011/h2011_Irene.html.

Page 2, top: U.S. map: Fry, J., Xian, G., Jin, S., Dewitz, J., Homer, C., Yang, L., Barnes, C., Herold, N., and Wickham, J., 2011, Completion of the 2006 National Land Cover Database for the conterminous United States: Photogrammetric Engineering \& Remote Sensing (PE\&RS), v. 77(9), p. 858-864.

Page 3, top: Red-cockaded woodpecker courtesy of Will Stuart

Photographs by Alan M. Cressler, USGS

Page 2, bottom: Hymenocallis coronaria (spider lily), Cahaba River, Hargrove Shoals, Cahaba National Wildlife Refuge, Alabama

Page 3, top: Viola palmata, early blue violet Anhinga anhinga (American darter), Shark Valley, Everglades National Park, Florida

Elliptio complanata (eastern elliptio, freshwater mussel) Hibiscus coccineus (scarlet rosemallow)

Pseudotriton ruber schencki (black-chinned red salamander)

Page 3, bottom: St. Vincent Sound, mainland side, beach erosion, Franklin County, Florida

Page 4, top: Fort Jefferson, Dry Tortugas National Park, Florida 